\title{
Consequences of manipulating gametes and embryos of ruminant species
}

\author{
T. G. McEvoy, C. J. Ashworth, J. A. Rooke and K. D. Sinclair \\ Scottish Agricultural College, Animal Biology Division, Craibstone Estate, Bucksburn, \\ Aberdeen AB21 9YA, UK
}

\begin{abstract}
During the past 12 years, ruminants have provided a focus for some significant advances in mammalian reproductive biotechnologies. Lambs were the first offspring generated after nuclear transfer of fetal or adult cells to enucleated oocytes, and many calves of pre-determined gender are today the result of commercialized semen sexing. In 1990, the birth of one calf provided living proof that even 'dead' spermatozoa can be paternal, whereas, more recently, a short-lived gaur calf and viable mouflon lamb represented a novel option for conservation of endangered species. As well as highlights, hazards have emerged, resulting in setbacks or developmental anomalies, such as those associated with the large offspring syndrome which encompasses a range of adverse fetal, placental and post-natal phenomena expressed in ruminants. In this review, the developmental and other consequences of applying manipulative procedures, such as assisted fertilization, semen sexing, cloning and gene transfer, to gametes and embryos from bovine, ovine and caprine species are considered. Although assisted fertilization techniques can overcome mammalian infertility, they also usurp natural gamete selection safeguards, but not always with impunity. In the case of manipulations such as cloning, and to a lesser extent gene transfer, it is evident that nuclear-cytoplasmic interactions and nuclear-mitochondrial DNA interdependences are at least partially damaged or destroyed with a view to reconstruction. Therefore, among surviving zygotes and embryos it is inevitable that the legacy is frequently one of altered genetic, epigenetic or cellular programmes and processes.
\end{abstract}

\section{Introduction}

The application of assisted reproductive technologies (ART) to ruminant species during the past 10 years has, in some cases, at least partly realized the potential attributed to them during the 1980s. In other cases, ART have facilitated advances towards research horizons then considered beyond reach. Transgenic ruminant animal production has been confined mainly to biopharmaceutical agendas at dedicated 'pharming' facilities and research institutions, whereas semen-sexing technology is now available in the UK. Most significantly, nuclear 
transfer myths and taboos have been cast aside, thanks to the births, at Roslin, of lambs derived from enucleated oocytes injected with nuclei from somatic fetal or adult cells. In recent years, using some of the technologies in tandem, there has been steady progress towards production, via intracytoplasmic sperm injection (ICSI), of lambs and calves of pre-determined sex (Catt et al., 1996; Hamano et al., 1999) and, via nuclear transfer, of gene-targeted sheep (McCreath et al., 2000). Progress in transgene technology can also influence ruminants indirectly, via plant breeding or modifications to rumen microflora (Robinson and McEvoy, 1999) but, as they do not involve mammalian gamete or embryo manipulation, these advances will not be featured here.

In this review, some of the outcomes and implications, and benefits and limitations, of gamete and embryo manipulation procedures as applied to ruminants will be considered. In so doing, we will not dwell on supporting technologies per se (for example, IVF and embryo culture), but instead will consider technologies that use physically disruptive, invasive or otherwise stressful manipulations of gametes or embryos. The importance of in vitro environments and their immediate and lasting effects on the development of ruminants, in particular, have been emphasized elsewhere (Young et al., 1998; McEvoy et al., 2000; Sinclair et al., 2000) and must not be underestimated.

Technologies that will be considered in this review include assisted fertilization procedures (notably ICSI), semen sexing, nuclear transfer and transgenic animal production.

\section{Assisted fertilization via gamete manipulation}

In vitro assisted fertilization procedures aimed at enhancing embryo production in conditions in which conventional IVF cannot or might not achieve the desired results have been developed primarily for application in humans. There has been less interest in respect of ruminants, partly because it is rarely either feasible or desirable to generate offspring from bulls, rams or bucks with poor fertility or significant semen quality limitations. However, in some circumstances it may be justified, for example when only immature spermatids are available post mortem or, perhaps, to facilitate sperm-mediated gene transfer (SMGT; discussed later) in certain circumstances.

Zona pellucida drilling, partial zona pellucida digestion (PZD), subzonal injection (SUZI) and ICSI are the options available in clinical IVF settings. Of these, ICSI has been most successful and, because the other techniques are quite likely to result in polyspermic fertilization, ICSI has generally superseded them.

\section{ICSI - application to ruminants}

The history of ICSI reached its first major milestone when Goto et al. (1990) reported the birth of a normal calf after injection of a 'killed' spermatozoon into a bovine oocyte (Table 1). Some years later, a male lamb was born after ICSI of a Y chromosome-bearing ovine spermatozoon (Catt et al., 1996) and, more recently, the same procedure generated caprine blastocysts (Keskintepe et al., 1997).

The usual consequence of ICSI, partly because of its invasive nature, is failure to generate offspring efficiently. For example, in the study reported by Catt et al. (1996), only one lamb was born after transfer of 251 oocytes to recipient ewes within $4 \mathrm{~h}$ after ICSI. Nevertheless, ICSI is a valuable procedure for generation of embryos in circumstances in which natural breeding or conventional IVF is not an option. Herein, however, lies a concern. The evolutionary forces that have shaped natural breeding practices among ruminants impose stringent selection pressures on the male gamete, and only the very fittest (in terms of maturity, morphology and motility) are permitted to reach the site of fertilization in vivo. The fact that ICSI bypasses 
Table 1. Summary of studies contributing to the application of intracytoplasmic sperm injection (ICSI) in domestic ruminants

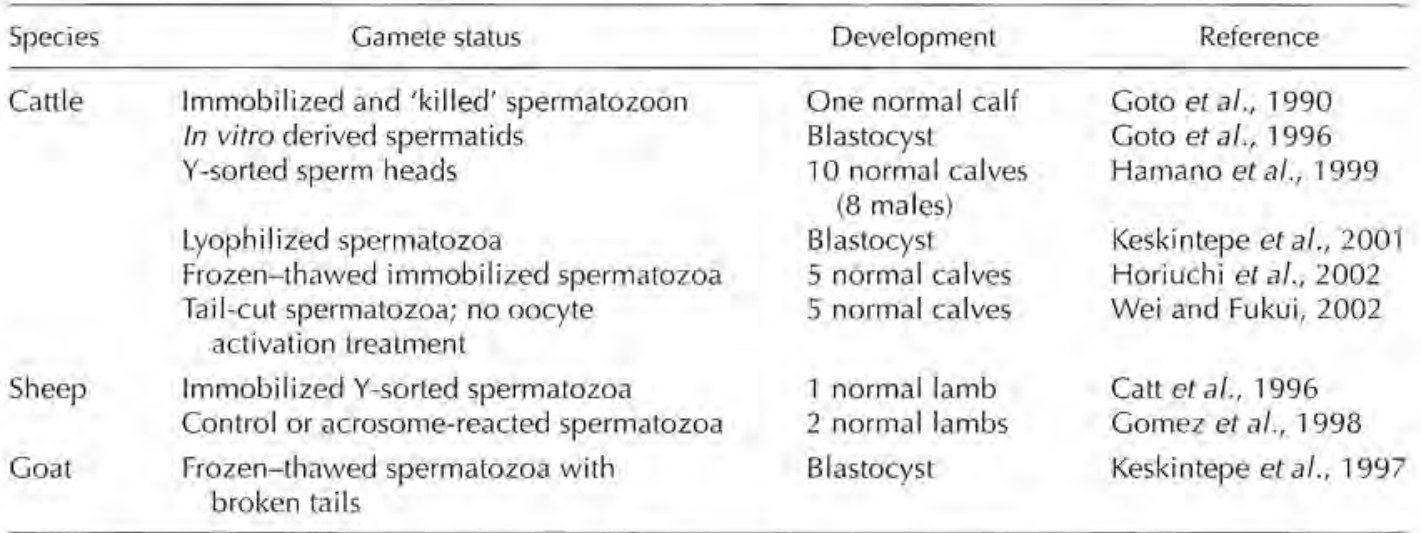

these selective processes has led some to outline the risks involved and, in effect, question the use of the process (Goto, 1997; Hewitson et al., 2000). Such questioning, particularly in the context of human clinical applications, has sometimes been countered, quite unnecessarily, by pejorative charges of promoting a eugenics agenda. Much more helpfully, some have been willing to engage in constructive debate; a notable and thought-provoking example (including rebuttals) is that between Lamb (1999) and Schlegel (1999). Although the stakes are not nearly so high in the context of ruminant reproduction, it is important to consider whether ICSI is likely to enhance or undermine reproduction (Fig. 1).

As it is a technically demanding and costly procedure, ICSI is unlikely to be used for commercial animal breeding. Horiuchi et al. (2002) suggested that ICSI might be used to maximize the progeny from costly semen straws, but we consider this to be improbable. Instead, ICSI is most applicable for conservation biology and genetic salvage, when only 'dead' spermatozoa or immature spermatids are available, or for application in tandem with specialist technologies such as gene transfer. In conservation biology, any risk associated with ICSI is probably outweighed by the threat of extinction or loss of a valued genotype, whereas for genetic salvage, significant investments and the limitations of alternative options could justify ICSI as a route for breeding specialized genotypes. It is possible, for example, that pronuclear microinjection of presumptive zygotes will be superseded to some extent by sperm-mediated gene transfer via ICSI in the near future (see later), not least because it is less technically demanding and, as noted by Perry et al. (1999), avoids the need for prior generation of presumptive zygotes.

The outcomes of ICSI, in terms of efficiency of generating embryos or offspring, are influenced by a number of factors including sperm pre-treatments, approaches to oocyte activation and injection-related hazards, such as meiotic spindle disruption (Rho et al., 1998; Hewitson et al., 1999; Wei and Fukui, 1999, 2002). Curiously, sperm viability in the conventional sense is not a significant factor. Immobilized and 'dead' spermatozoa are at least as successful in generating blastocysts or offspring. Indeed, Wei and Fukui (1999) and Yanagimachi (2001) observed that ICSI with immobilized spermatozoa improved fertilization.

A concern about ICSI, particularly when the procedure involves tail-scoring or removal of the tail, is that exposure of the 'damaged' gamete to culture medium may be detrimental to 


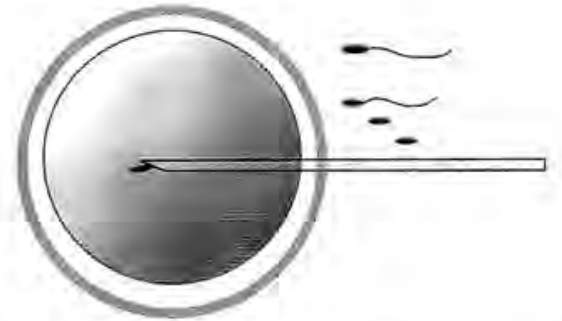

Method A: One-step procedure with sharply pointed injection needle, to introduce male gamete, with or without sperm tail

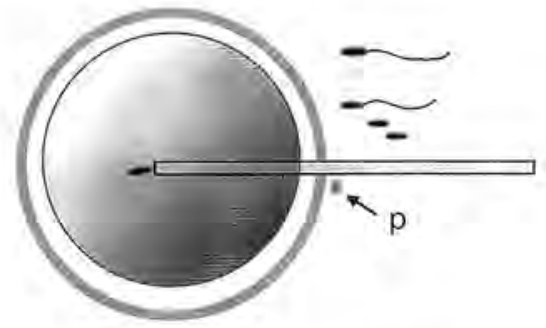

Method B: Two-step, pulse-driven procedure with straight-ended needle, first removing zona pellucida plug $(p)$ and then introducing male gamete

\begin{tabular}{|l|l|l|l|}
\cline { 2 - 4 } \multicolumn{1}{c|}{} & \multicolumn{3}{c|}{ Some ICSI scenarios } \\
\hline Male gamete category & $\begin{array}{l}\text { Dead spermatozoa or } \\
\text { immature spermatids }\end{array}$ & $\begin{array}{l}\text { Lyophilised } \\
\text { spermatozoa }\end{array}$ & $\begin{array}{l}\text { Spermatozoa carrying } \\
\text { 'foreign' DNA }\end{array}$ \\
\hline Benefit & $\begin{array}{l}\text { Genetic salvage and } \\
\text { conservation }\end{array}$ & $\begin{array}{l}\text { More efficient gamete } \\
\text { storage }\end{array}$ & $\begin{array}{l}\text { Transgenic animal } \\
\text { production }\end{array}$ \\
\hline Hazard & $\begin{array}{l}\text { Propagate inferior or } \\
\text { lethal genotypes }\end{array}$ & $\begin{array}{l}\text { Viability not } \\
\text { predetermined }\end{array}$ & $\begin{array}{l}\text { Contaminant DNA } \\
\text { uptake }\end{array}$ \\
\hline
\end{tabular}

Fig. 1. The advantages and disadvantages of intracytoplasmic sperm injection (ICSI).

the stability of chromosomes exposed by the injury inflicted (Kusakabe et al., 2001), because the ionic composition and other properties of conventional media do not reflect the intracellular milieu of the spermatozoon (Yanagimachi, 2001). Studies with non-ruminants have indicated that damage can be limited by reducing $\mathrm{Na}^{+}$and increasing $\mathrm{K}^{+}$concentrations (Tateno et al, 2000).

Other possible adverse consequences of ICSI are inadvertent disease transmission (Cummins, 2001) or introduction of unwanted exogenous DNA into injected oocytes after exposure of spermatozoa, especially if damaged, to serum or albumin in conventional media. These are real risks, firstly because serum is considered by some to be desirable for other reasons: for example, it has been suggested that the presence of serum (15\% inclusion) reduced the incidence of egg degeneration in the immediate aftermath of bovine and murine ICSI procedures (Keskintepe and Brackett, 2000). Secondly, although the extent to which extraneous DNA might persist during embryogenesis is unknown, it is precisely such persistence that provides the basis for sperm-mediated gene transfer procedures.

ICSI also risks other consequences relating to DNA persistence, for example when fertilization is achieved by injecting spermatozoa that have damaged nuclear DNA. As reported by Sakkas et al. (2000), ICSI with such spermatozoa offers contrasting scenarios. Firstly, paternal nuclear DNA may not be repaired after injection and fertilization may fail to occur. Secondly, DNA repair may be sufficient to ensure that subsequent development is entirely normal. Thirdly, however, partial DNA repair may facilitate fertilization, but lead to later losses or the generation of abnormal offspring. The report of Rho et al. (1998) in which ICSI-derived bovine blastocyst transfer resulted in six confirmed pregnancies (including fetal heartbeat detection) at day 49 of gestation but no 


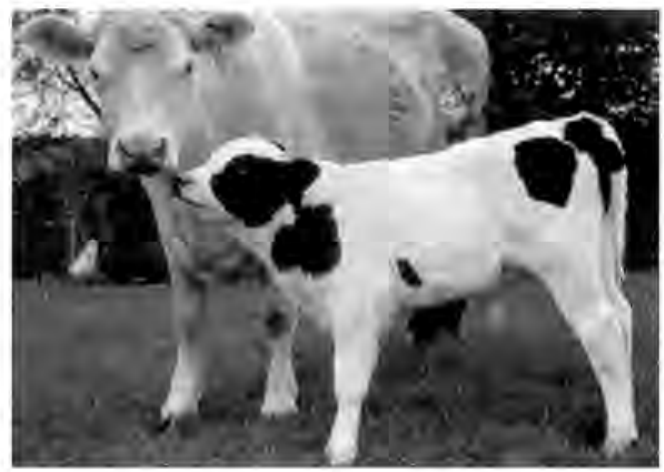

Fig. 2. In the 10 years since the first 'semen sexed' calves were produced (by D. Cran and coworkers) at Cambridge in the UK, sperm-based gender preselection technology has advanced to the extent that approximately 50000 calves have been born worldwide after inseminations with sex-sorted semen, mostly on commercial farms (photograph courtesy of Farmers Weekly).

survival to term indicates that ICSI-derived fetuses or their placentae or both were subnormal.

\section{ICSI - anomalies and opportunities}

Whatever the incidence or severity of long-term consequences, there is compelling evidence from elegant primate studies that 'fertilization' events immediately after ICSI are not analogous to those after normal penetration of the oocyte by intact spermatozoa. Some differences are linked to the persistence, during ICSI, of components of the spermatozoon that normally do not enter the cytoplasm after sperm-oocyte fusion. Hewitson et al. (1999) noted that the pattern of rhesus monkey sperm decondensation after ICSI was impeded by retention of vesicle-associated membrane protein (VAMP), a constituent of the sperm acrosome, and that migration of oocyte-derived nuclear mitotic apparatus (NuMA) into condensed regions of paternal chromatin was delayed. Such anomalies, they concluded, could mean that ICSI per se might be responsible for observed increases in chromosomal aberrations.

One potentially valuable consequence of ICSI is that, in future, preservation of male gametes may not require cryo-storage in liquid nitrogen which, as noted by Kusakabe et al. (2001), is costly, subject to failure and carries a contamination risk. Instead, because motility is not essential, cheaper and more transport-friendly drying options, which need only to maintain nuclear integrity of spermatozoa, should become a viable proposition. For example, Keskintepe et al. (2001) have demonstrated that ICSI with lyophilized spermatozoa is capable of generating morula-blastocyst-stage bovine embryos (20\% yield) in vitro.

Finally, as outlined by St John (2002), ICSI shares with both nuclear transfer and cytoplasmic transfer technologies the possibility that mitochondrial inheritance is not exclusively uniparental (Smith et al., 2000), a topic that will be addressed later in this review.

\section{Gender preselection via semen sorting}

The facility to predetermine the gender of cattle with approximately $90 \%$ accuracy has become a commercial reality in the UK in recent years (Fig. 2), using technologies that separate 


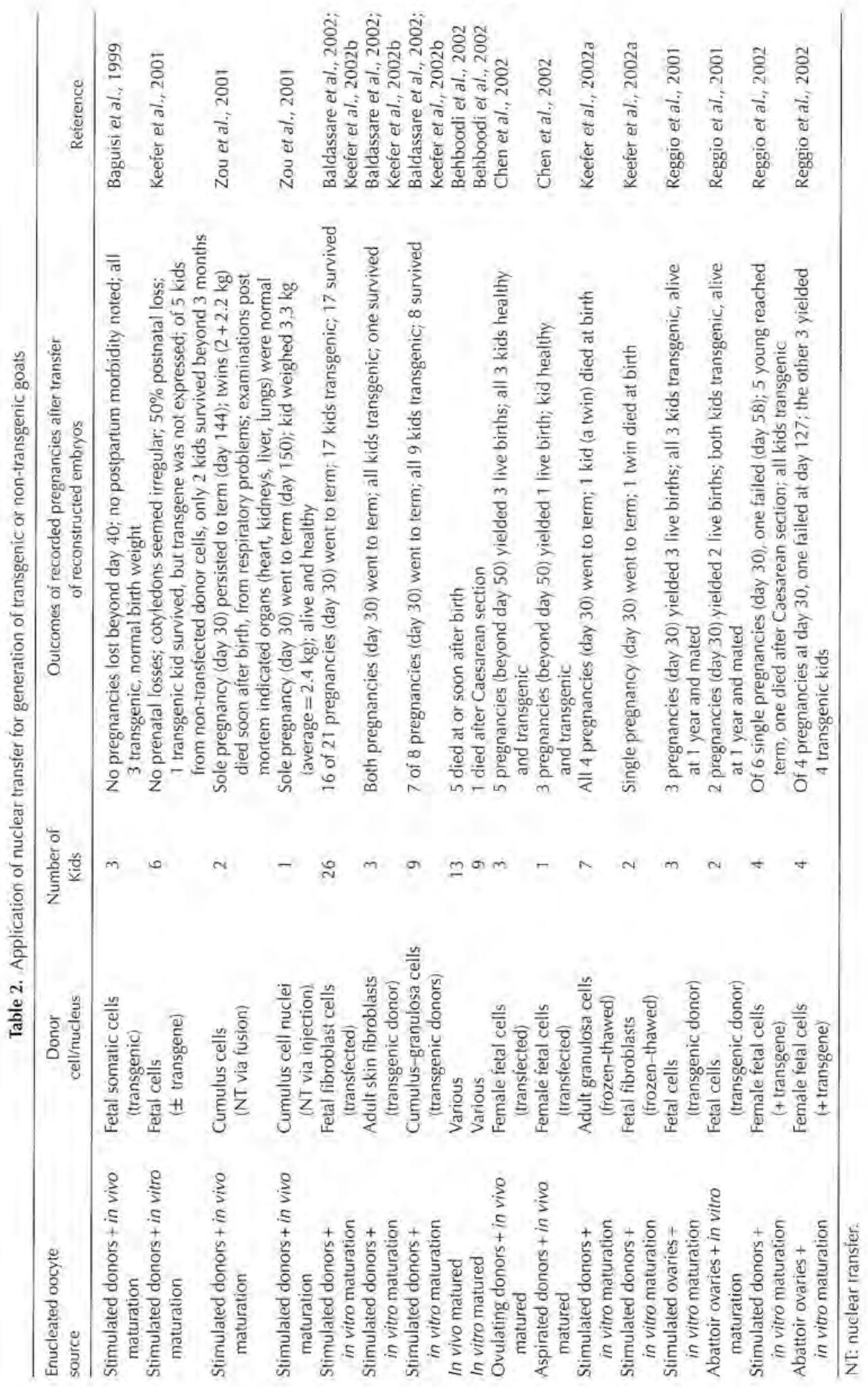


$X$ - and $Y$-chromosome-bearing spermatozoa on the basis of differences in their DNA content (Johnson, 2000). To date, there is little or no evidence of any attributable adverse effects among offspring born after IVF or Al of cattle or sheep with 'sorted' semen (Cran and Johnson, 1996; Cran et al., 1997; Seidel et al., 1999, 2002). However, semen sorting does reduce sperm viability (Caballero et al., 2002) and, in a recent study, Garner and Suh (2002) showed that mechanical stress, UV laser illumination and exposure to a fluorescent dye with high affinity to DNA all contributed to the demise, after cryopreservation and thawing, of up to two-thirds of sorted spermatozoa. Most damage was attributed to the mechanical stresses imposed, and sire-to-sire variations were also noted.

\section{Nuclear transfer technology}

Nuclear transfer in the context of agriculture, where cattle are the primary candidates, is the subject of a separate review in this volume (Wells, this supplement), so emphasis here is on consequences arising either in smaller ruminants (sheep and goat) or from non-agricultural applications, such as the generation of inter-species (Bovidae or Ovidae) hybrids.

Production of nuclear transfer (NT)-derived ruminants is an inefficient process, and most fused 'donor cell-oocyte' couplets fail to generate viable offspring after transfer. Prenatal fetal losses are considerable in sheep (Wells et al, 1997; Wilmut et al., 1997) but, although not always avoided (Reggio et al., 2002), have been less prevalent in goats. In a number of goat NT studies in which pregnancies had been confirmed by detection of fetal heartbeats at day 30 or day 40 of gestation (Table 2), subsequent losses did not occur prenatally (Baguisi et al., 1999; Keefer et al., 2001, 2002a; Reggio et al., 2001; Zou et al., 2001). As a result, Keefer et al. (2001) speculated that non-occurrence of prenatal fetal loss was due to avoidance of prolonged in vitro culture of NT embryos or, alternatively, to a greater ability of caprine cytoplasts to reprogramme donor nuclei, thereby safeguarding subsequent development in utero. Whether goats differ innately from other species in terms of oocyte resilience after the traumas associated with nuclear transfer must remain in doubt until more conclusive evidence becomes available. Moreover, such a scenario is hardly supported by the fact that goats (Table 2) do not appear to differ from sheep or cattle with respect to susceptibility to peripartum or post-natal losses associated with NT-derived offspring.

There is compelling evidence to indicate that, after nuclear transfer, fetal losses are due to significant developmental retardation and placental inadequacies (De Sousa et al., 2001). Deficiencies in chorioallantoic vascularization, although probably correctly viewed as the ultimate cause of pre-term losses, are themselves the result of earlier aberrations in the developmental blueprint of NT-derived embryos. Indeed, the fact that losses can occur at all stages and in various guises, ranging from gross degeneration of preimplantation embryos to sudden post-natal death of apparently normal offspring, confirms that NT procedures are frequently responsible for fundamental and far-reaching disruption of developmental norms. Intuitively, it could hardly be otherwise, given that the reconstructed egg comprises a severely traumatized host cytoplast fused to a donor cell (or nucleus) with which, to a greater or lesser extent depending on its origin, it is virtually incompatible from the outset. Therefore, the more remarkable phenomenon is that, against all the odds, NT sometimes results in the generation of viable offspring. Whether those current odds can be shortened in favour of enhanced efficiencies is a question occupying many minds and underlying recent and ongoing investigations at genetic, epigenetic and cellular developmental levels.

The relevant genetic and epigenetic investigations are primarily concerned with identifying and manipulating mechanisms and circumstances that regulate and programme gene expression and cellular differentiation, nol only near the time of NT but also during later stages of 
the development of the new individual. Campbell (1999) outlined the effect of the stage of the cell cycle, in both the recipient oocyte and donor nucleus, on maintenance of correct ploidy in the reconstructed egg and on essential reprogramming-remodelling of the transferred nucleus. Although neither is fully understood nor reliably controllable thus far, a key to success is the establishment of a proper 'dialogue' between the donor nucleus and recipient cytoplasm (Fulka et al., 2001) to orchestrate normal development in the reconstructed embryo. When circumstances do not permit the necessary choreography, the consequences are manifest as a spectrum of anomalies, ranging from immediate or later deaths to non-lethal developmental aberrations analogous to those of the large offspring syndrome in ruminants (Young et al., 1998; Sinclair et al., 2000; McEvoy et al., 2001; Bertolini and Anderson, 2002). Research investigations, prompted initially by the large offspring syndrome but of relevance to NT outcomes in ruminant species, have considered the effects of epigenetic modifications in the early embryo on later development (Young and Fairburn, 2000). As a result, it has been shown that in vitro culture of intact sheep embryos can influence methylation of imprinted genes (Young et al., 2001). Even more recently, Fairburn et al. (2002) reported that, for both sheep and cattle, there were increased methylation levels (relative to 'normal' embryos) in significant numbers of NT-derived blastocysts. As noted by De Sousa et al. (2001), fetal and placental defects later in development may be due to aberrant imprinting of one or more genes in NT-derived sheep embryos. The same authors observed that, although pathologies associated with NT-derived sheep and cattle affected diverse fetal tissues (including heart and liver) as well as placentae, it is possible that these have a common origin, namely embryonic mesoderm. However, as yet, the prospect of a panacea for the developmental defects now associated with nuclear transfer in ruminants seems remote.

\section{Nuclear transfer and mitochondrial DNA inheritance}

One reason for suspecting that there may not be a single 'cure' for the defects associated with NT-derived embryos is that, despite the 'clone' pseudonym, no two cytoplast-nucleus (or cytoplast-cell) couplets are identical. For example, recipient cell cytoplasm will differ, as will the extent of heteroplasmy, when donor cells (rather than just nuclei) are fused to the cytoplast. Therein lies another possible consequence of nuclear transfer, given that the reconstructed egg contains mitochondrial DNA (mtDNA) from two sources. This procedure differs from the normal pattern of mtDNA inheritance which is uniparental and homoplasmic, due both to the demise of paternally derived mitochondria after fertilization and, on the basis of genetic bottleneck theory, the transmission of only a few molecules of maternal mitochondria which subsequently 'colonize' the next generation (Smith et al,, 2000; Cummins, 2001). Mitochondria undertake crucial functions within the embryo, notably oxidative phosphorylation which relies on a competent electron-transport chain. As emphasized by St John (2002), proper function of the electron-transport chain requires complementary expression of genes encoded by the nuclear genome and mitochondrial genome. Evidently, where such symbiosis is threatened, respiratory deficiency and disease could ensue. Whether mtDNA heteroplasmy, as a result of mixing and persistence of mitochondria from host oocyte and donor cell cytoplasm, constitutes a threat in NT-derived ruminants remains uncertain. Although there is evidence of heteroplasmy among calves generated via nuclear transfer (Hiendleder et al., 1999), tests of some tissues from NT-derived sheep ( $n=10$, including Dolly) revealed no evidence that mitochondria from the somatic donor cells were present (Evans et al., 1999).

Mitochondrial inheritance scenarios are most intriguing when considering NT as a tool to generate interspecific hybrid animals or to conserve endangered species via transfer of 
somatic cells to enucleated oocytes of 'near' relatives. Evidently neither could be pursued if heteroplasmy were both inevitable and lethal.

\section{Interspecies nuclear transfer}

Smith et al. (2000) reported that, in cattle, when Nellore (Bos indicus) cells of embryonic origin were introduced into enucleated Holstein (Bos taurus) oocytes, Bos indicus mtDNA was detectable after fusion (approximately $4 \%$ ) and at day 50 of gestation (approximately $2 \%$; in one fetus), but was not detectable in the NT-derived live offspring at birth. In a separate bovid interspecies NT programme, Lanza et al. (2000) found that transfer of somatic cells from a gaur bull (wild ox; Bos gaurus; $2 n=58$ ) into enucleated domestic cattle (Bos taurus; $2 n=60$ ) oocytes generated reconstructed eggs, of which $12 \%$ became blastocysts, and almost one in five of these generated fetuses after transfer to surrogate recipients. Three fetuses were electively recovered (day $46, n=1$; day 54 , twins) and subsequent analysis of 11 tissue types revealed that mtDNA was exclusively Bos taurus, whereas cytogenetic analysis indicated that all three fetuses had Bos gaurus nuclear origins. Consequently, the fetuses were genetic chimaeras rather than true Bos gaurus individuals.

The most promising success to date was that reported by Loi et al. (2001), who generated inter-species embryos by injecting enucleated oocytes of domestic sheep (Ovis aries) with granulosa cells collected post mortem from adult female mouflons (Ovis orientalis musimon). The ensuing pregnancies $(n=2)$ resulted in the live birth of an apparently normal (but 'hybrid') mouflon $(\mathrm{mtDNA}=O$. aries; nuclear origin $=O$. o. musimon). Other interspecies ruminant NT studies generated blastocysts after transfer of buffalo (Bubalus bubalis) somatic cells to enucleated bovine (Bos indicus) oocytes (Saikhun et al., 2002), and a single pregnancy (lost by day 60 of gestation) from a reconstructed embryo generated by transfer of an endangered argali wild sheep (Ovis ammon; $2 n=56$ ) somatic cell to an enucleated domestic sheep (Ovis aries; $2 \mathrm{n}=54$ ) oocyte (White et al., 1999).

Evidently, interspecies nuclear transfer technology could yet provide some valuable opportunities for the rescue, and perhaps the eventual revival, of endangered ruminant species. However, any such NT project proposals should first be evaluated rigorously (Fig. 3), using realistic predictions of probable outcomes. When alternative conservation strategies could suffice, especially if these are simpler or more promising, scientists should resist the greater 'glamour' associated with costly and sometimes contentious cloning programmes. This is because, in terms of conservation, successes will be very short-lived unless NT-derived interspecies offspring can survive to breeding age and beyond (Lee, 2001; Vogel, 2001). The extent to which genotype of available surrogate dams could influence survival in utero is an additional consideration (see Lanza et al., 2000; Hammer et al., 2001). Genetic proximity or otherwise of ancestral links, for example among sheep (Hiendleder et al., 2002), may be a key determinant of success or failure.

\section{Transgenic animal production}

Almost two decades since Hammer et al. (1985) reported the production of transgenic lambs (as well as pigs and rabbits) after gene transfer via pronuclear microinjection, this direct route of transgene delivery, despite its very low efficiency, continues to be used to generate ruminant offspring, and exogenous DNA is randomly integrated into the genome of the individual. Although not necessary in all species, the injection procedure is preceded by routine centrifugation ( $13000-15000 \mathrm{~g}$ ) of the recently fertilized egg if, as in cattle, endogenous lipids would otherwise obscure the pronuclei (Pursel et al., 1989; McEvoy et al., 1992). 


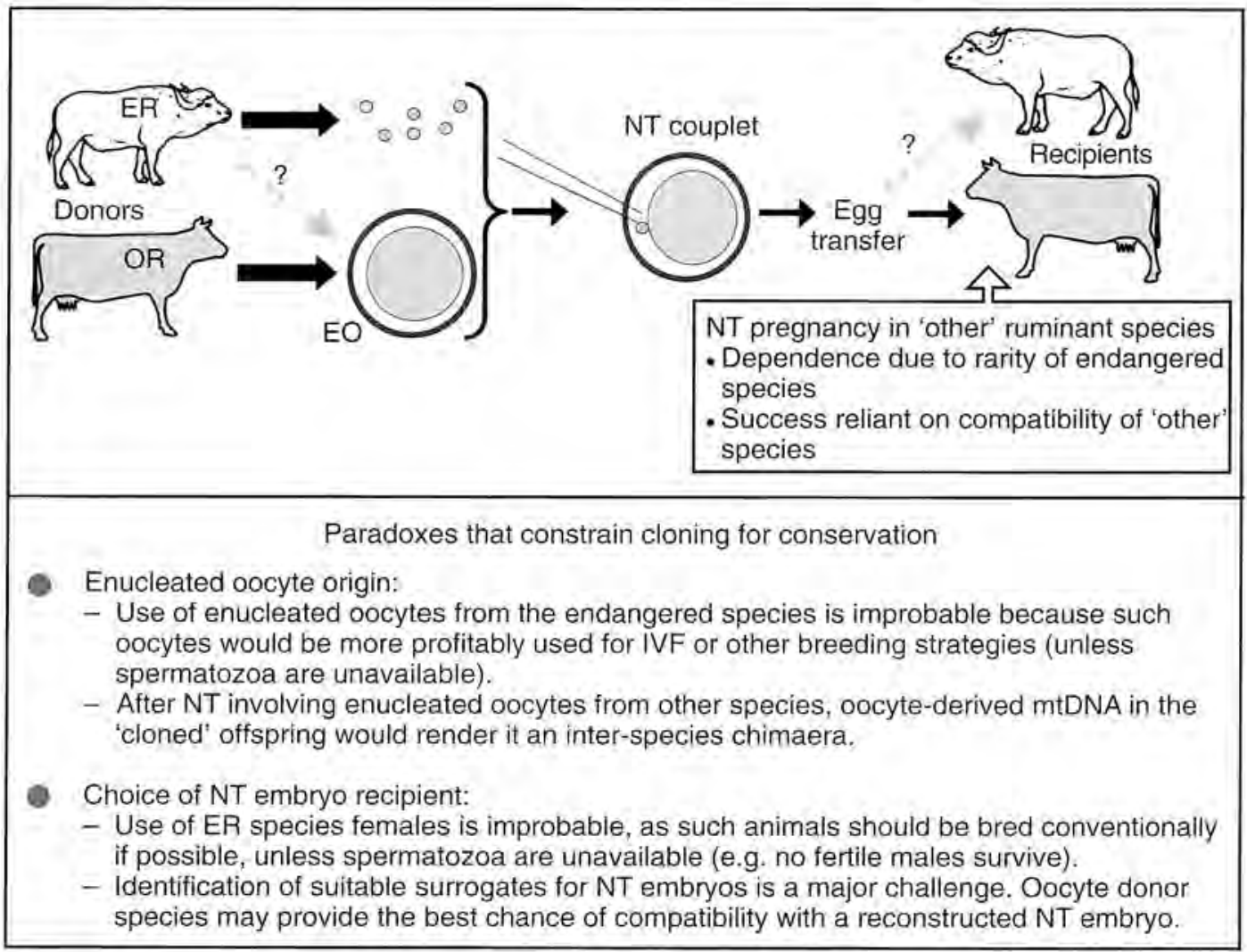

Fig. 3. Consideration of viability of use of nuclear transfer (NT) for conserving endangered ruminants. ER: endangered ruminant; $O R$ : other ruminant; EO: enucleated oocyte; mtDNA: mitochondrial DNA.

Among the consequences of transgenic animal production via pronuclear microinjection, in addition to intended genetic modifications, there have been many unexpected and adverse side-effects, including arthritis, infertility, peptic ulcers and severely reduced body-fat reserves (Pursel et al., 1989). It became apparent that many of these disabilities were due to indiscriminate or inappropriate transgene expression (in terms of developmental stage or tissue or organ site) or knock-on effects. Much subsequent research effort was devoted therefore to refining gene constructs to generate healthy offspring more effectively which would express the transgene not only benignly, but also, if possible, in the desired site- and stage-specific manner. For example, in programmes aimed at modifying milk composition in ruminants, $\beta$-lactoglobulin and various casein gene promoter sequences help to ensure specific targeting of expression of associated structural DNA sequences to the mammary gland (Murray and Maga, 1999).

Despite improvements in gene constructs, from the point of view of avoiding detrimental outcomes or sometimes improving transgene regulation in individuals that were genetically transformed, the efficiency of generating transgenic ruminants after micro-injection of recently fertilized eggs has remained very low. Recent reviews confirm that, for cattle, goats and sheep, less than $1 \%$ of microinjected eggs transferred to recipients resulted in the births of transgenic calves, kids and lambs (Pinkert and Murray, 1999; Niemann and Kues, 2000; Baldassare et al., 2002). Therefore, it is no surprise that, in the 1980 s and 1990 s, considerable thought and effort was invested in devising alternative procedures that might hold greater promise for 


\section{Current methods:}

- Pronuclear gene injection to generate founder animals

- Nuclear transfer (NT), after donor cell transformation in vitro, to generate founder animals

- Nuclear transfer (using donor cells from founder stock) to generate genomic copies of the proven genotype

\section{Some key applications:}

- Confer resistance to mastitis

- Modify milk to enhance its suitability for consumption by humans, especially infants

- Generate biopharmaceutical proteins in cows, goats or sheep

- Alter milk properties to facilitate processing and storage

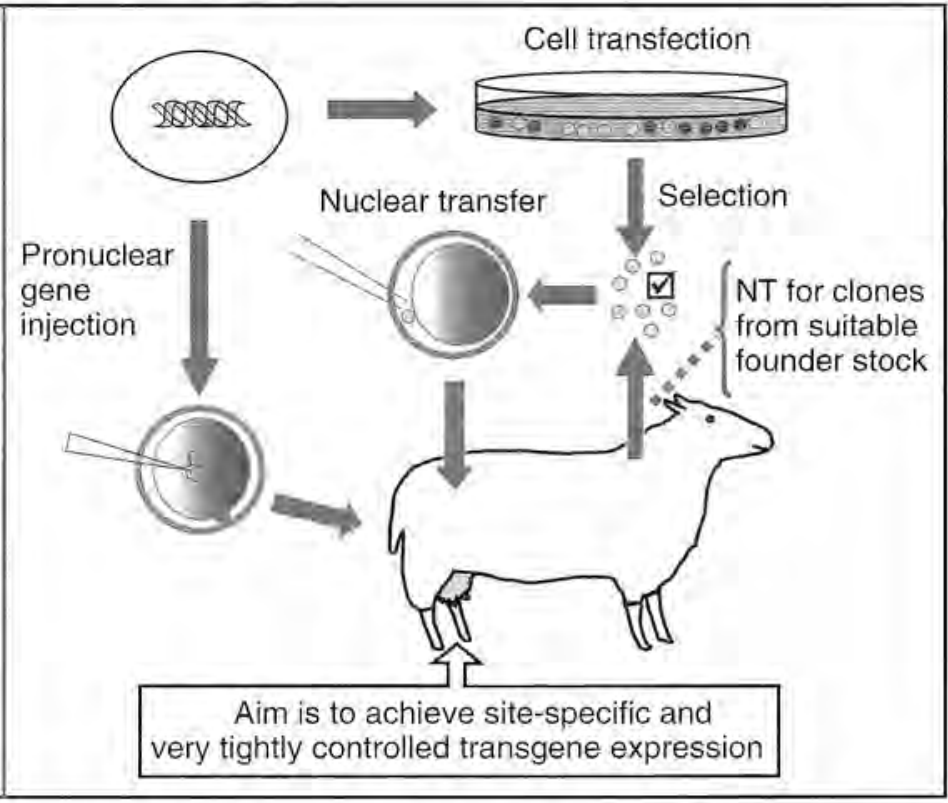

Fig. 4. Gene transfer technology - modification of milk composition or mammary disease resistance in ruminants.

generation and propagation of transgenic animals. The surprise, echoed in doubts expressed elsewhere, was the emergence of two contrasting strategies for transgenic animal production. The first, aimed at de novo generation of transgenic individuals, relies on sperm-mediated gene transfer (SMGT) to mammalian oocytes. In theory, the intent here is to use spermatozoa as exogenous DNA vectors during the natural process of egg fertilization; in practice, fertilization in such instances is sometimes achieved via ICSI (Perry et al., 1999). The second strategy, intended for propagation and de novo generation of transgenic animals, apparently defies natural processes, involving as it does the transfer of transformed somatic cells or nuclei (including those from adult donors) to enucleated oocytes (Fig. 4).

\section{Sperm-mediated gene transfer}

Sperm-mediated gene transfer was first reported more than 30 years ago in rabbits (Brackett et al, 1971), but significant controversy did not arise until Lavitrano et al. (1989) indicated production of genetically transformed mice by this route. The incredulity and disbelief that this could happen was reflected in a letter from some of the principal doubters, published later in that year, after failed attempts to repeat this work in a number of other laboratories (Brinster et al, 1989). To their credit, the Italian workers persisted (Wall, 2002) and others also took up the challenge. For many, the report by Perry et al. (1999), who used the procedure in tandem with ICSI, provided confirmation that SMGT can be achieved in mammals. Reports relating to SMGT in ruminants are scarce to date but notable. Shemesh et al. (2000), using restriction enzyme-mediated integration (REMI), demonstrated that a transgene coding for green fluorescence protein (GFP) was integrated into genomic DNA of bovine spermatozoa which, when used for artificial insemination, resulted in production of transgenic calves. Moreover, after IVF with REMI-transfected spermatozoa, approximately $30 \%$ of resultant morulae expressed 
the GFP transgene. In a separate study, Rieth et al. (2000) demonstrated the production of transgenic bovine embryos after IVF with spermatozoa previously electroporated to enhance DNA uptake. One limitation was that the percentage of eggs developing beyond the 16-cell stage was reduced after IVF with electroporated DNA-treated spermatozoa $(27 \%$ and $34 \%$ for different constructs; $43 \%$ for control spermatozoa).

\section{Transgenic ruminants via nuclear transfer}

Despite the various limitations of nuclear transfer as applied to ruminant animals (McEvoy et al., 2001), a major justification for pursuing it is that, especially in the context of therapeutic protein production or better understanding of disease, it offers the means whereby precise genetic changes can be achieved in livestock (Wilmut et al., 1999). The key example to date is the report by McCreath et al. (2000) which refers to the production of 14 lambs born alive in a targeted gene transfer study. Unfortunately, half of these lambs died within a week and only three survived for more than 3 months. Investigations revealed a high incidence of kidney defects and brain and liver pathologies, but McCreath et al. (2000) concluded that some feature of cell treatment or nuclear transfer was more likely to be at fault than gene targeting per se. This conclusion was based on the fact that the observed defects mirrored those recorded after nuclear transfer involving the same cells without gene targeting (Schnieke et al., 1997).

Hill et al. (1999) studied pathologies in NT-derived transgenic bovine fetuses and calves $(n=13)$ and also concluded that the NT procedure or embryo culture in vitro or both procedures contributed to the observed developmental abnormalities. Cibelli et al. (1998a) reported the production of three healthy transgenic calves after nuclear transfer of fetal fibroblasts expressing a marker transgene, but significant losses during the first trimester were also a feature, In an alternative procedure, the same authors also generated nine chimaeric transgenic calves after transfer of genetically modified embryonic stem-like cells into day 3 embryos (Cibelli et al., 1998b). These transformed ES-like cells had been generated either conventionally or via NT of transfected fetal fibroblasts into enucleated oocytes. The latter approach gave rise to seven calves after transfer of only ten blastocysts to surrogate recipients. Of these, six expressed the transgene in one or more tissues and all were healthy.

Two studies have investigated the production of transgenic goats after nuclear transfer of genetically transformed cells. In one study by Baguisi et al. (1999), three healthy kids were found to be carrying a transgene coding for expression of recombinant human antithrombin III (rhAT) targeted to the mammary gland. Milk from one of the kids was tested and found to contain the gene product. Keefer et al. (2001) reported the birth of a female goat after NT of a cell from a transgenic (eGFP) cell line; PCR analysis confirmed the presence of the transgene. In both of these studies of goats, developmental aberrations were less evident than in either cattle or sheep, perhaps reflecting, as discussed earlier, benefits from shorter-term culture in vitro or species differences in terms of susceptibility to the various manipulations.

\section{Conclusions}

Ruminant animals have been the focus for a range of significant scientific and technical advances via gamete and embryo manipulation in the past decade. Some, particularly semen sexing, promise to influence animal breeding and commercial agriculture significantly. Other advances, such as bio-pharmaceutical protein production by transgenic animals, will be principally or even solely applicable to specialized industries. When widespread application in conventional agriculture is the goal, technical inefficiencies may perhaps be 


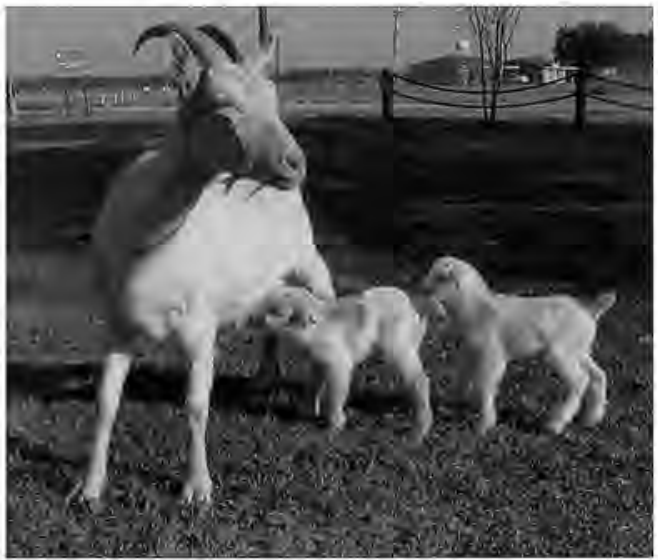

Fig. 5. Ruminants and assisted reproductive technologies (ART) - key is to produce healthy offspring. Viable offspring from a transgenic nuclear transfer goat (photograph courtesy of $\mathrm{R}$. Godke, Louisiana State University).

accommodated, but tolerance of adverse developmental consequences is very low. However, in other circumstances it may be considered justifiable to use technologies such as nuclear transfer, despite the fact that these are inherently predisposed to triggering a high incidence of developmental defects among resultant offspring. For example, when the generation of even a few healthy transgenic sheep or goats (Fig. 5) could hold the promise of affordable cures for otherwise intractable human diseases, scientists and the public they serve may consider the risks and failures en route to be worthwhile. Nevertheless, there is at all times a duty of damage limitation and a need to avoid unnecessary hazards. As stated by McEvoy et al. (2001), culture conditions and constituents associated with physical manipulations need to be made safer, especially in the case of manipulations that, either necessarily or by default, injure or expose spermatozoa, oocytes or embryos. Otherwise, hostile environments will contribute to abnormal development. Simply stated, only when in vitro conditions are optimized will adverse consequences of gamete and embryo manipulations be minimized. For procedures that are traumatic, some adverse outcomes will remain inevitable. Nevertheless, further significant achievements, benefits and successes will accrue from the ongoing efforts and expertise invested in reproductive technologies for ruminant species.

SAC receives funding from the Scottish Executive Environment and Rural Affairs Department. Large Offspring studies referred to in the text were funded by the Department for Environment, Food and Rural Affairs and carried out in collaboration with colleagues at Roslin Institute (Edinburgh).

\section{References}

Baguisi A, Behboodi E, Melican DT et al. (1999) Production of goats by somatic cell nuclear transfer Nature Biotechnology 17 456-461

Baldassare H, Wang B, Kafidi N, Keefer C, Lazaris A and Karatzas CN (2002) Advances in the production and propagation of transgenic goats using laparoscopic ovum pick-up and in vitro embryo production technologies Theriogenology 57 275-284
Behboodi E, Ayres SL, Reggio BC, O'Coin MD, Gavin WG, Denniston RS, Landry AM, Meade HM and Echelard Y (2002) Pregnancy profile and health status of goats derived by somatic cell nuclear transfer Theriogenology 57395 (Abstract)

Bertolini M and Anderson GB (2002) The placenta as a contributor to production of large calves Theriogenology 57 181-187 
Brackett BG, Baranska W, Sawicki W and Koprowski H (1971) Uptake of heterologous genome by mammalian spermatozoa and its transfer to ova through fertilization Proceedings National Academy of Sciences USA 68 353-357

Brinster RL, Sandgren EP, Behringer RR and Palmiter RD (1989) No simple solution for making transgenic mice Cell 59 239-241

Caballero J, Aguilar J, Cattaneo L and Perez S (2002) Effect of incubation and flow cytometry on membrane integrity and mitochondrial function of bovine sperm Theriogenology $\mathbf{5 7} 744$ (Abstract)

Campbell KHS (1999) Nuclear equivalence, nuclear transfer and the cell cycle Cloning 1 3-15

Catt SL, Catt JW, Gomez MC, Maxwell WMC and Evans G (1996) Birth of a male lamb derived from an in vitro matured oocyte fertilized by intracytoplasmic injection of a single presumptive male sperm Veterinary Record 139 494-495

Chen LH, Behboodi E, Reggio BC, Shen MF, O'Coin MD, Destrempes MM, Sansinena MJ, Nims SD, Denniston RS and Meade HM (2002) Generation of transgenic goats from transfected fibroblast cell lines for the production of a malaria vaccine antigen Theriogenology 57777 (Abstract)

Cibelli JB, Stice SL, Golueke PJ, Kane J, Jerry J, Blackwell C, Ponce de Leon FA and Robl JM (1998a) Cloned transgenic calves produced from non-quiescent fetal fibroblasts Science $2801256-$ 1258

Cibelli JB, Stice SL, Golueke PJ, Kane J, Jerry J, Blackwell C, Ponce de Leon FA and Robl JM (1998b) Transgenic bovine chimeric offspring produced from somatic cell-derived stem-like cells Nature Biotechnology 16 642-646

Cran DG and Johnson LA (1996) The predetermination of embryonic sex using flow cytometrically separated $X$ and $Y$ spermatozoa Human Reproduction Update $2355-363$

Cran DG, McKelvey WAC, King ME, Dolman DF, McEvoy TG, Broadbent PJ and Robinson JJ (1997) Production of lambs by low dose intrauterine insemination with flow cytometrically sorted and unsorted semen Theriogenology 47267 (Abstract)

Cummins JM (2001) Cytoplasmic inheritance and its implications for animal biotechnology Theriogenology 55 1381-1399

De Sousa PA, King TJ, Harkness L, Young LE, Walker SK and Wilmut I (2001) Evaluation of gestational deficiencies in cloned sheep fetuses and placentae Biology of Reproduction 6523-30

Evans MJ, Gurer C, Loike JD, Wilmut I, Schnieke AE and Schon EA (1999) Mitochondrial DNA genotypes in nuclear transfer-derived cloned sheep Nature Genetics 23 90-93

Fairburn HR, Young LE and Hendrich BD (2002) Epigenetic reprogramming: how now, cloned cow? Current Biology 12 R68-R70
Fulka J, Jr, Loi P, Ledda S, Moor RM and Fulka J (2001) Nucleus transier in mammals: how the oocyte cytoplasm modifies the transferred nucleus. Theriogenology 55 1373-1380

Garner DL and Suh TK (2002) Effect of Hoechst 33342 staining and laser illumination on the viability of sex-sorted bovine sperm Theriogenology 57746 (Abstract)

Gomez MC, Catt JW, Evans G and Maxwell WM (1998) Cleavage, development and competence of sheep embryos fertilized by intracytoplasmic sperm injection and in vitro fertilization Theriogenology 49 1143-1154

Goto K (1997) Current status and future of micromanipulation-assisted fertilization in animals and humans Journal of Reproduction and Development $43 \quad 107-119$

Goto K, Kinoshida A, Takuma Y and Ogawa K (1990) Fertilization of bovine oocytes by the injection of immobilised, killed spermatozoa The Veterinary Record $127517-520$

Goto K, Kinoshida A, Nakanisha Y and Ogawa K (1996) Blastocyst formation following intracytoplasmic injection of in vitro derived spermatids into bovine oocytes Human Reproduction $11824-829$

Hamano K, Li X, Qian X, Funauchi K, Furudate $M$ and Minato $Y$ (1999) Gender preselection in cattle with intracytoplasmically injected, flow cytometrically sorted sperm heads Biology of Reproduction 60 1194-1197

Hammer RE, Pursel VG, Rexroad CE, Jr, Wall RJ, Bolt D], Ebert KM, Palmiter RD and Brinster RL (1985) Production of transgenic rabbits, sheep and pigs by microinjection Nature 315 680-683

Hammer Cl, Tyler HD, Loskutoff NM, Armstrong DL, Funk DJ, Lindsey BR and Simmons LG (2001) Compromised development of calves (Bos gaurus) derived from in vitro-generated embryos and transferred interspecifically into domestic cattle (Bos taurus) Theriogenology 55 1447-1455

Hewitson L, Dominko T, Takahashi D et al. (1999) Unique checkpoints during the first cell cycle of fertilization after intracytoplasmic sperm injection in rhesus monkeys Nature Medicine 5 431433

Hewitson L, Simerly C, Dominko D and Schatten G (2000) Cellular and molecular events after in vitro fertilization and intracytoplasmic sperm injection Theriogenology 53 95-104

Hiendleder S, Schmutz SM, Erhardt G, Green RD and Plante $Y$ (1999) Transmitochondrial differences and varying levels of heteroplasmy in nuclear transfer cloned cattle Molecular Reproduction and Development 54 24-31

Hiendleder S, Kaupe B, Wassmuth R and Janke A (2002) Molecular analysis of wild and domestic sheep questions current nomenclature and provides evidence for domestication from two different subspecies 
Proceedings of the Royal Society of London. Series B. Biological Sciences $269893-904$

Hill JR, Roussel AJ, Cibelli JB et al. (1999) Clinical and pathological features of cloned transgenic calves and fetuses (13 case studies) Theriogenology 51 14511465

Horiuchi T, Emuta C, Yamauchi Y, Oikawa T, Numabe T and Yanagimachi R (2002) Birth of normal calves after intracytoplasmic sperm injection of bovine oocytes: a methodological approach Theriogenology 57 1013-1024

Johnson LA (2000) Sexing mammalian sperm for production of offspring: the state-of-the-art Animal Reproduction Science 60-61 93-107

Keefer CL, Baldassare H, Keyston R et al. (2001) Generation of dwarf goat (Capra hircus) clones following nuclear transfer with transfected and non-transfected fetal fibroblasts and in vitro-matured oocytes Biology of Reproduction 64 849-856

Keefer CL, Keyston R, Lazaris A et al. (2002a) Produc tion of cloned goats after nuclear transfer using adult somatic cells Biology of Reproduction 66 199-203

Keefer C, Lazaris A, Keyston R et al. (2002b) Cloning using somatic cells for the production and propagation of transgenic Nigerian dwarf and dwari-crosssbred goats Theriogenology 57422 (Abstract)

Keskintepe L and Brackett BG (2000) Cryopreservation of bovine blastocysts obtained by intracytoplasmic sperm injection Theriogenology 53 1041-1052

Keskintepe 1, Morton PC, Smith SE, Tucker MJ, Simplicio AA and Brackett BG (1997) Caprine blastocyst formation following intracytoplasmic sperm injection and defined culture Zygote 5 261-265

Keskintepe L, Hasan A, Khan I and Stice SL (2001) Bovine embryo development after lyophilised sperm injection Theriogenology 55505 (Abstract)

Kusakabe $H$, Szczygiel MA, Whittingham DG and Yanagimachi R (2001) Maintenance of genetic integrity in frozen and freeze-dried mouse spermatozoa Proceedings National Academy of Sciences USA 98 $13501-13506$

Lamb DJ (1999) Debate: is ICSI a genetic time bomb? Yes Journal of Andrology 20 23-33

Lanza RP, Cibelli JB, Diaz F, Moraes CT, Farin PW, Farin CE, Hammer Cl, West MD and Damiani P (2000) Cloning of an endangered species (Bos gaurus) using interspecies nuclear transfer Cloning 2 79-90

Lavitrano M, Camaioni A, Fazio VM, Dolci S, Farace MG and Spadafora C (1989) Sperm cells as vectors for introducing foreign DNA into eggs: genetic transformation of mice Cell 57 717-723

Lee $\mathrm{K}(2001)$ Can cloning save endangered species? Current Biology 11 R245-R246

Loi P, Ptak G, Barboni B, Fulka J, Jr, Cappai P and Clinton M (2001) Genetic rescue of an endangered mammal by cross-species nuclear transfer using postmortem somatic cells Nature Biotechnology $19962-$ 964
McCreath KJ, Howcroft I, Campbell KH, Colman A, Schnieke AE and Kind AJ (2000) Production of genetargeted sheep by nuclear transfer from cultured somatic cells Nature 405 1066-1069

McEvoy TG, Robinson JJ and Sreenan IM (1992) A role for transgenic animals in food production? Trends in Food Science and Technology 3 294-302

McEvoy TG, Sinclair KD, Young LE, Wilmut I and Robinson II (2000) Large offspring syndrome and other consequences of ruminant embryo culture in vitro: relevance to blastocyst culture in human ART Human Fertility $3238-246$

McEvoy TG, Robinson J and Sinclair KD (2001) Developmental consequences of embryo and cell manipulation in mice and farm animals Reproduction 122 507-518

Murray JD and Maga EA (1999) Changing the composition and properties of milk. In Transgenic Animals in Agriculture pp 193-208 Eds ID Murray, GB Anderson, AM Oberbauer and MM McGloughlin. CABI Publishing, Wallingford, UK

Niemann $\mathrm{H}$ and Kues WA (2000) Transgenic livestock: premises and promises Animal Reproduction Science 60-61 277-293

Perry AC, Wakayama I, Kishikawa H, Kasai T, Okabe M, Toyoda $\mathrm{Y}$ and Yanagimachi R (1999) Mammalian transgenesis by intracytoplasmic sperm injection Science $2841180-1183$

Pinkert CA and Murray JD (1999) Transgenic farm animals. In Transgenic Animals in Agriculture pp 1-18 Eds JD Murray, GB Anderson, AM Oberbauer and MM McGloughlin. CABI Publishing, Wallingford, UK

Pursel VG, Pinkert CA, Miller KF, Bolt DJ, Campbell RG, Palmiter RD, Brinster RL and Hammer RE (1989) Genetic engineering of livestock Science $2441281-1288$

Reggio BC, James AN, Green HL, Gavin WC, Behboodi E, Echelard Y and Godke RA (2001) Cloned transgenic offspring resulting from somatic cell nuclear transfer in the goat: oocytes derived from both follicle-stimulating hormone-stimulated and nonstimulated abattoir-derived donors Biology of Reproduction $\mathbf{6 5}$ 1528-1533

Reggio BC, Green HL, Sansinena M, Chen LH, Behboodi E, Denniston RS, Echelard Y and Godke RA (2002) Production of cloned transgenic goats as a potential source for human pharmaceuticals Theriogenology 57. 445 (Abstract)

Rho G-J, Kawarsky S, Johnson WH, Kochhar K and Betteridge KJ (1998) Sperm and oocyte treatments to improve the formation of male and female pronuclei and subsequent development following intracytoplasmic sperm injection into bovine oocytes Biology of Reproduction 59 918-924

Rieth A, Pothier F and Sirard M-A (2000) Electroporation of bovine spermatozoa to carry DNA containing highly repetitive sequences into oocytes and detection of homologous recombination events 
Molecular Reproduction and Development 57338 345

Robinson IJ and McEvoy TG (1999) Opportunities and constraints into the next millennium. In Protein Metabolism and Nutrition pp 265-282 Eds GE Lobley, A White and JC MacRae. Wageningen Pers, Wageningen, The Netherlands

Saikhun J, Pavasuthipaisit K, Jaruansuwan $M$ and Kitiyanant Y (2002) Xenonuclear transplantation of buffalo (Bubalus bubalis) fetal and adult somatic cell nuclei into bovine (Bos indicus) oocyte cytoplasm and their subsequent development Theriogenology 57 1829-1837

Sakkas D, Manicardi GC, Bizzaro D and Bianchi PG (2000) Possible consequences of performing intracytoplasmic sperm injection (ICSI) with sperm possessing nuclear DNA damage Human Fertility 3 26-30

Schlegel PN (1999) Debate: is ICSI a genetic time bomb? No: ICSI is safe and effective Journal of Andrology 20 18-22

Schnieke AE, Kind AJ, Ritchie WA, Mycock K, Scott AR, Ritchie M, Wilmut I, Colman A and Campbell KHS (1997) Human factor IX transgenic sheep produced by transfer of nuclei from transfected fetal fibroblasts Science $2782130-2133$

Seidel GE, Jr, Schenk IL, Herickhoff LA, Doyle SP, Brink Z, Green RD and Cran DG (1999) Insemination of heifers with sexed sperm Theriogenology 52 1407-1420

Seidel GE, Jr, Brink Z, Lu KH, Flint AF, De La TorreSanchez JF and Suh TK (2002) Normality of calves produced from IVF with sexed sperm and culturing embryos with insulin Theriogenology 57754 (Abstract)

Shemesh M, Gurevich M, Harel-Markowitz $E$, Benvenisti L, Shore LS and Stram Y (2000) Gene integration into bovine sperm genome and its expression in transgenic offspring Molecular Reproduction and Development 56 306-308

Sinclair KD, Young LE, Wilmut I and McEvoy TG (2000) In utero overgrowth in ruminants following embryo culture: lessons from mice and a warning to men Human Reproduction 15 Supplement 5 68-86

Smith LC, Bordignon V, Garcia IM and Meirelles FV (2000) Mitochondrial genotype segregation and effects during mammalian development: applications to biotechnology Theriogenology 53 3546

St John JC (2002) The transmission of mitochondrial DNA following assisted reproductive techniques Theriogenology 57 109-123
Tateno H, Kimura $\mathrm{Y}$ and Yanagimachi R (2000) Sonication per se is not as deleterious to sperm chromosomes as previously inferred Biology of Reproduction $63341-346$

Vogel G (2001) Cloned gaur a short-lived success Science 29140

Wall RJ (2002) New gene transfer methods Theriogeno$\log y 57$ 189-201

Wei $\mathbf{H}$ and Fukui $\mathbf{Y}$ (1999) Effects of bull, sperm type and sperm pretreatment on male pronuclear formation after intracyloplasmic sperm injection in cattle Reproduction, Fertility and Development 11 59-65

Wei $\mathrm{H}$ and Fukui Y (2002) Births of calves derived from intracytoplasmic sperm injection (ICSI) without exogenous oocyte activation treatment Theriogenology 57758 (Abstract)

Wells DN, Misica PM, Day AM and Tervit HR (1997) Production of cloned lambs from an established embryonic cell line: a comparison belween in vivo and in vitro-matured cytoplasts Biology of Reproduction $57385-393$

White KL, Bunch TD, Mitalipov S and Reed WA (1999) Establishment of pregnancy after the transfer of nuclear transfer embryos produced from the fusion of Argali (Ovis ammon) nuclei into domestic sheep (Ovis aries) enucleated oocytes Cloning 1 47-54

Wilmut I, Schnieke AE, MCWhir J, Kind A and Campbell KHS (1997) Viable offspring derived from fetal and adult mammalian cells Nature $385810-813$

Wilmut I, Schnieke E, McWhir J, Kind AJ, Colman A and Campbell KHS (1999) Nuclear transfer in the production of transgenic farm animals. In Transgenic Animals in Agriculture pp 67-78 Eds JD Murray, GB Anderson, AM Oberbauer and MM McGloughlin. CABI Publishing, Wallingford, UK

Yanagimachi R (2001) Gamete manipulation for development: new methods for conception Reproduction, Fertility and Development 13 3-14

Young LE and Fairburn HR (2000) Improving the safety of embryo technologies: possible role of genomic imprinting Theriogenology 53 627-648

Young LE, Sinclair KD and Wilmut I (1998) Large offspring syndrome in cattle and sheep Reviews of Reproduction 3 155-163

Young LE, Fernandes K, McEvoy TG et al. (2001) Epigenetic change in IGF2R is associated with fetal overgrowth after sheep embryo culture Nature Genetics $27153-154$

Zou X, Chen Y, Wang Y et al. (2001) Production of cloned goats from enucleated oocytes injected with cumulus cell nuclei or fused with cumulus cells Cloning 3 31-37 